\title{
Design of high-speed planing hulls for the improvement of resistance and seakeeping performance
}

\author{
Dong Jin Kim ${ }^{1}$, Sun Young Kim ${ }^{1}$, Young Jun You ${ }^{2}$ \\ Key Pyo Rhee ${ }^{2}$, Seong Hwan Kim ${ }^{1}$ and Yeon Gyu Kim ${ }^{1}$ \\ ${ }^{I}$ Maritime \& Ocean Engineering Research Institute, Korea Institute of Ocean Science \& Technology, Daejeon, Korea \\ ${ }^{2}$ Department of Naval Architecture and Ocean Engineering, Seoul National University, Seoul, Korea
}

\begin{abstract}
High-speed vessels require good resistance and seakeeping performance for safe operations in rough seas. The resistance and seakeeping performance of high-speed vessels varies significantly depending on their hull forms. In this study, three planing hulls that have almost the same displacement and principal dimension are designed and the hydrodynamic characteristics of those hulls are estimated by high-speed model tests. All model ships are deep-V type planing hulls. The bows of no.2 and no.3 model ships are designed to be advantageous for wave-piercing in rough water. No.2 and no.3 model ships have concave and straight forebody cross-sections, respectively. And length-to-beam ratios of no. 2 and no. 3 models are larger than that of no. 1 model. In calm water tests, running attitude and resistance of model ships are measured at various speeds. And motion tests in regular waves are performed to measure the heave and pitch motion responses of the model ships. The required power of no.1 (VPS) model is smallest, but its vertical motion amplitudes in waves are the largest. No.2 (VWC) model shows the smallest motion amplitudes in waves, but needs the greatest power at high speed. The resistance and seakeeping performance of no.3 (VWS) model ship are the middle of three model ships, respectively. And in regular waves, no.1 model ship experiences 'fly over' phenomena around its resonant frequency. Vertical accelerations at specific locations such as F.P., center of gravity of model ships are measured at their resonant frequency. It is necessary to measure accelerations by accelerometers or other devices in model tests for the accurate prediction of vertical accelerations in real ships.
\end{abstract}

KEY WORDS: Planing hull; Running attitude; Resistance performance; Seakeeping behavior; Vertical acceleration.

\section{INTRODUCTION}

High-speed vessels are mostly supported by buoyancy at low speed, but at high speed, they are raised by additional hydrodynamic lifts or aerodynamic forces in order to reduce their wetted surface area and resistance. A planing craft is one of the most general types of high-speed vessels, and considerable portions of their weights are supported by the lift forces acting on the hull bottom. The characteristics of planing hull shapes, such as deadrise angles, and the shape or the number of chines, have significant influences on the hydrodynamic performance of planing hulls. Therefore, planing hulls should be designed to meet desired performance. Generally, the resistance or seakeeping performance of planing crafts may be predicted by model tests in the initial design stage.

There are some previous researches about high-speed model tests in calm water or in waves. Fridsma (1969) carried out experimental investigations about the effects of deadrise angle, displacement, length to beam ratio, and location of center of

Corresponding author: Dong Jin Kim

e-mail:djkim@kiost.ac 
gravity on the running attitudes of planing hulls in calm water and their motion responses or vertical accelerations in regular waves. Savitsky and Brown (1976) proposed empirical formulas for calm water resistance, added resistance and bow acceleration in waves and lifts acting on stern wedges of prismatic planing hulls. Gerritsma et al. (1992) carried out high-speed model tests for the prediction of resistance and stability of some planing crafts. Ikeda et al. $(1995,1996)$ and Katayama et al. (2000) set up an unmanned high-speed towing carriage, and then performed various captive model tests or motion measuring tests with that carriage. Lee et al. (2005), Kim et al. (2006) tried to improve the resistance performance of high-speed vessels through the model tests. Kim et al. (2009a, 2009b) performed high-speed model tests for measuring running attitudes in calm water and vertical motion responses in regular waves. In particular, most domestic researches were focused on one area between resistance and seakeeping performance. Planing hulls need to be designed with consideration of various hydrodynamic characteristics, and if necessary, those hull forms should be modified to improve resistance or seakeeping performance in the initial design stage.

A desired planing vessel in this research is to run at Froude number 3.25 in calm water, and operate in rough water, above sea state 3, so good resistance and seakeeping performance are required. Three hull forms which have almost the same principal dimensions are designed, and model tests in calm water and in waves are carried out to analyze their resistance performance and seakeeping behavior. A high-speed towing carriage in Seoul National University is used to perform the model tests. The running attitudes and resistance are simultaneously measured with various Froude number in calm water tests. Heave and pitch motions are measured in regular waves with various wave lengths, and the effects of hull forms on seakeeping behavior are analyzed. In addition, vertical accelerations on specific positions of the models are measured around the resonance frequencies and compared with each other. Although there are some limitations during the model tests, it is possible to estimate the hydrodynamic performance of real ships qualitatively. Required improvement in the model test is specifically mentioned in the sections hereafter.

\section{HIGH SPEED TOWING SYSTEM}

Fig. 1 shows the plan view of a high-speed towing carriage in Seoul National University towing tank (Length $\times$ Breadth $\times$ Depth : $117 \mathrm{~m} \times 8 \mathrm{~m} \times 3.5 \mathrm{~m}$ ). Maximum speed of the carriage is $10 \mathrm{~m} / \mathrm{sec}$. And its weight is about $600 \mathrm{~kg} f$. Right and left ends of the carriage are supported by wheels on rails, one end is towed by a wire connected to a servo motor.

Fig. 2 shows the side view of a vertical motion measuring device. A towing point is located at the center of gravity in the longitudinal direction, and on the thrust line in the vertical direction. Heave and pitch motions of the model ship are measured by potentiometers.

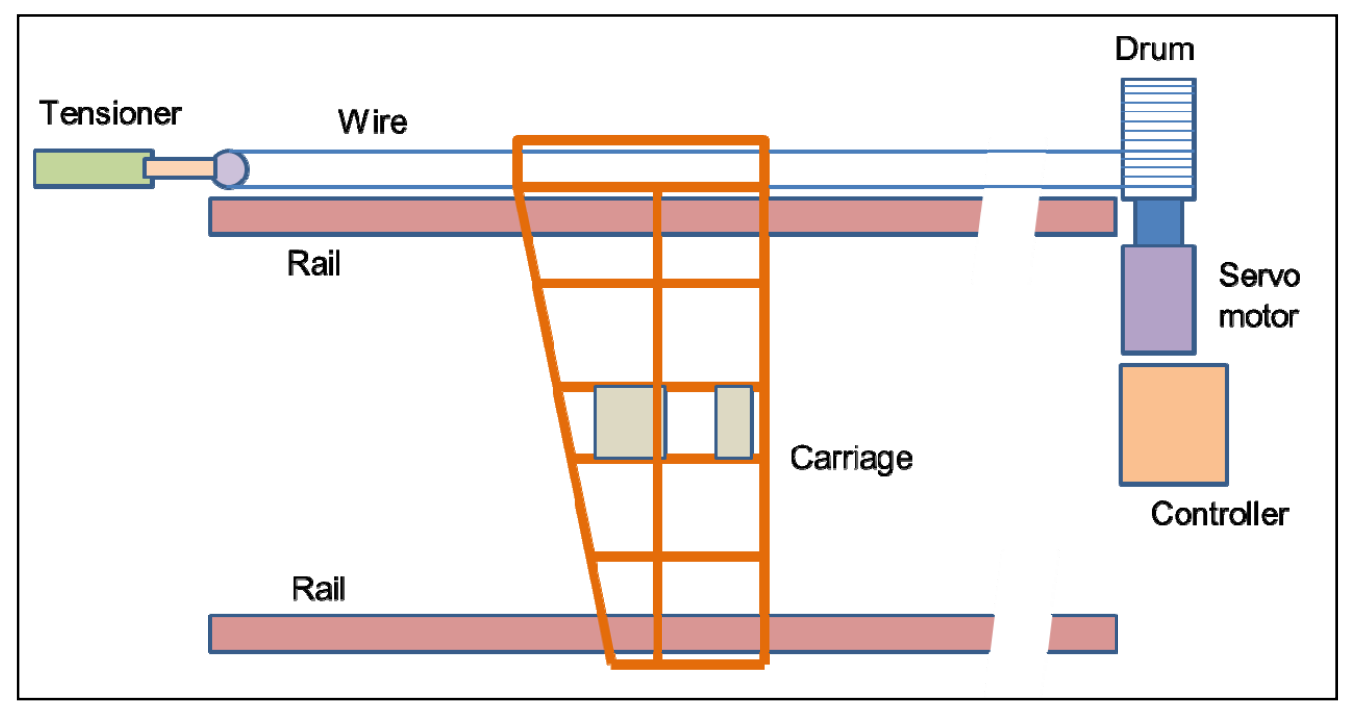

Fig. 1 Plan view of a high-speed towing carriage. 


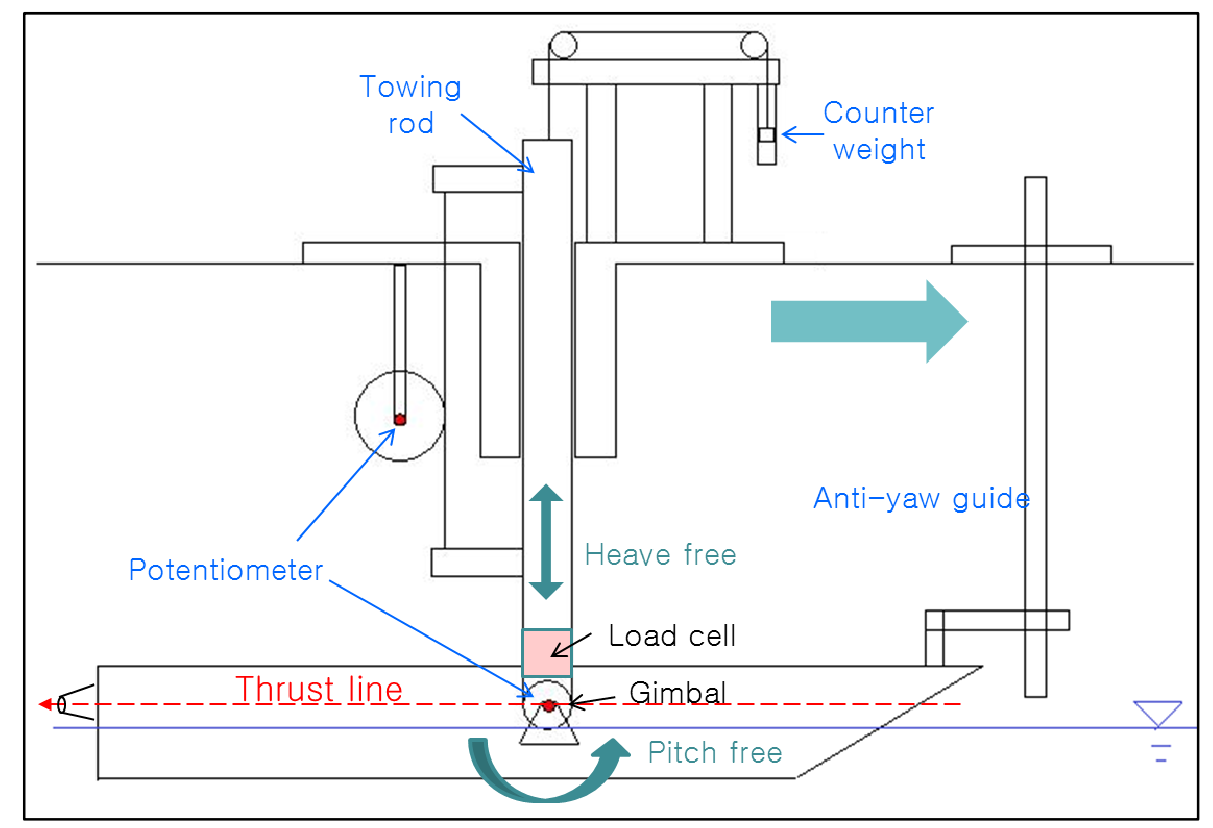

Fig. 2 Test setup for free-to-heave and pitch experiments.

In previous model tests, the towing point of a model ship was a simple hinge type in order that the model ship was free to pitch motion. Even though the model ship was trimmed, the towing direction was always the same as the advance direction of a towing carriage, in other words, the forward direction parallel to the free surface. Propulsion system is fixed on the vessel, so the thrust direction is inclined when the model ship is trimmed. A new gimbal is developed so that the model ship can be towed in the inclined thrust direction when the model ship is trimmed while running.

The operating mechanism of the new gimbal is shown in Fig. 3. Towing force is delivered from the cylinder to the rotation axis of a model ship via a bearing. The bearing cannot deliver the tangential force, so the towing force is only delivered in the normal direction, in other words, in the trimmed thrust direction.

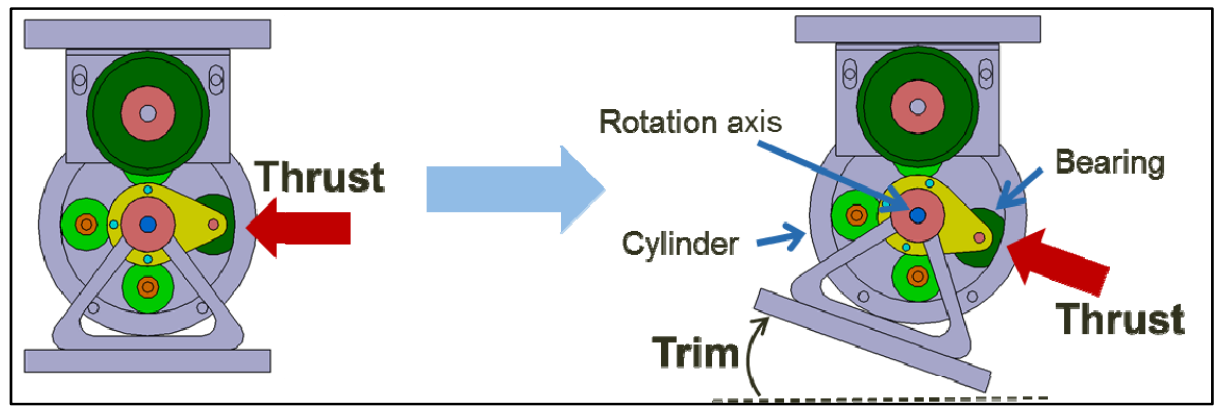

Fig. 3 Operation mechanism of the new gimbal.

The towing force is measured by a load cell which is located at the bottom of the towing rod. Measured force in the direction parallel to the free surface is converted to the model ship resistance in the thrust direction, corresponding to the running attitude of a model. An anti-yaw guide is installed around the bow of a model in order to prevent its yaw motion.

The towing rod is counter-balanced by the counter weight, so there are no effects of its weight on the displacement or the running attitude of a model at steady state in calm water. But in the model tests in waves, the towing rod and the counter weight do have influence on the motion of a model ship. It is predicted that the resonant frequency of a model ship is different from that of a real ship. The weights of the towing rod and the counter weight are respectively $4.4 \mathrm{kgf}$, so the sum of both weights is almost the same as the model ship weight. Especially in the heave motion, there is no change of restoring force, and inertia force is doubled, since the inertia of the towing rod and the balance weight is added. In that case, motion frequency is changed to $70 \%$ of an original value. Therefore it is predicted that the heave resonant frequency of a model ship in the present model 
tests is about 0.7 times of the resonant frequency of a real ship.

This study is focused on the qualitative comparison of hydrodynamic performance of each model ship. Meaningful results can be obtained by the model tests under the same conditions in spite of limitations on the test device. Limitations in the model tests should be considered when a real ship is designed.

\section{HULL FORM DEVELOPMENT CONCEPT AND PROCEDURE}

Three model ships are designed and those hydrodynamic characteristics are estimated by high-speed model tests. All model ships are hard-chine planing mono-hulls. Body plans of three model ships are shown in Fig. 4.

Main characteristics of hull shapes for three model ships are shown in Table 1. All model ships are deep-V types. The bows of no. 2 and no. 3 model are designed to be favorable for wave-piercing motions in rough water. Forebody sections of no. 1 and no. 3 model ships are designed as straight shapes, and that of no.2 model ships are concave shapes. If ' $\mathrm{V}$ ' is short for deep- $\mathrm{V}$ type, ' $\mathrm{P}$ ' and ' $\mathrm{W}$ ' is short for planing and wave-piercing, and ' $\mathrm{S}$ ' and ' $\mathrm{C}$ ' is short for straight and concave section shape, then no.1, no.2 and no.3 model ships can be named as VPS, VWC, and VWS as shown in Table 1.

Table 1 Characteristics of hull shapes of model ships.

\begin{tabular}{|c|c|c|c|}
\hline & No.1 model & No.2 model & No.3 model \\
\hline Whole section shape & deep-V & deep-V & deep-V \\
\hline $\begin{array}{c}\text { Motions in waves (In particular, } \\
\text { due to effects of forebody shape) }\end{array}$ & (just planing) & wave-piercing & wave-piercing \\
\hline Section shape of forebody & straight & concave & straight \\
\hline Model name & $\downarrow$ & $\downarrow$ & $\downarrow$ \\
& V.P.S. & V.W.C. & V.W.S. \\
\hline
\end{tabular}
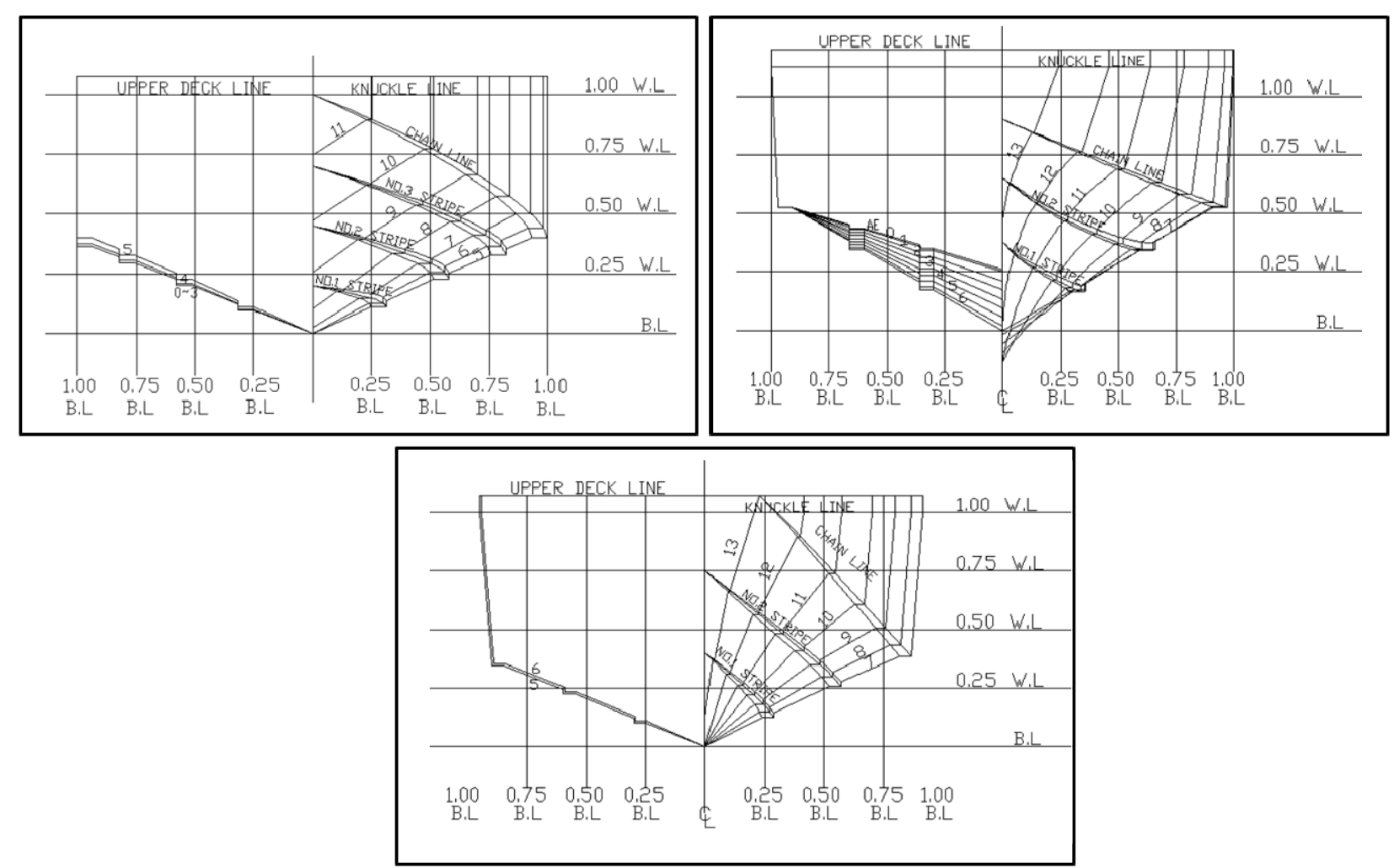

Fig. 4 Body plans of no.1 (VPS; upper left), no.2 (VWC; upper right), and no.3 (VWS; lower) model ships. 
Table 2 Principal dimension of model ships.

\begin{tabular}{|c|c|c|c|c|}
\hline Dimension & Unit & VPS (No.1 model) & VWC (No.2 model) & VWS (No.3 model) \\
\hline Length overall; LOA & Meter & 0.927 & 1.092 & 1.123 \\
\hline Length waterline; LWL & Meter & 0.796 & 1.026 & 0.292 \\
\hline Breadth overall & Meter & 0.308 & 0.308 & 0.072 \\
\hline Draft & Meter & 0.080 & 0.087 & 9.467 \\
\hline Weight & Kgf & 9.103 & 9.467 & 3.872 \\
\hline L/B (LWL / Chine breadth) & - & 2.586 & 3.334 & 20 \\
\hline Deadrise angle at A.P. & Degree & 20 & 30 & 22 \\
\hline Deadrise angle at midship & Degree & 23 & 80 & 75 \\
\hline Deadrise angle at F.P. & Degree & 32 & & 20 \\
\hline
\end{tabular}

Principal dimensions of them are shown in Table 2. Scale ratios of the model ship and the real ship are the same, 1/6.5. Maximum speed of the real ship is 45 knots. For the same Froude number of a real ship, corresponding maximum towing speed of the model ship is $9.08 \mathrm{~m} / \mathrm{sec}$.

In general, when deadrise angles of a planing hull with vee-bottom get smaller, trim angle is decreased and the hull rises up higher so that it shows good resistance performance. But its vertical motion amplitude in rough water becomes larger, and the course-keeping ability gets worse. On the other hand, when deadrise angles are larger, seakeeping performance and coursekeeping ability of the planing hull improve, but its resistance performance becomes worse. Excessive deadrise angles have control difficult at low speeds and reduce the transverse stability when the hull is planing. Therefore, proper deadrise angles should be selected with consideration of hydrodynamic performance of the planing hull. Furthermore, planing hulls may have various cross-section shapes such as straight, convex, concave, etc.. It is focused on the conceptual design for a small planing hull in this study. So afterbody cross-sections of the hulls are designed as straight shapes which show typical characteristics of planing surfaces.

All model ships are designed with the variations of deadrise angle, section shape, and length-to-beam ratio. And the number or the arrangement angle of spray rails and the forefoot contour are also varied. VPS (no.1) model is designed to minimize the required power. It has the smallest deadrise angle among three model ships. Deadrise angle on the afterbody is around 20 degrees, it is gradually increased on the forebody, and is 32 degrees at F.P.. Every cross-section is the straight shape. The keel line begins curving up toward the bow at 55\% of the LWL forward of the transom as shown in Fig. 5. Length-to-beam ratio of VPS model is 2.586, and is the smallest among three model ships. In other words, VPS model has the largest aspect ratio, and it is most advantageous to rise up due to the lift. There are 3 pairs of spray rails on the hull bottom to generate additional lifts. And Fig. 5 shows that the bottom of the stern of VPS model is extended backward about $2.9 \%$ of the length of waterline so that the trim angle decreases, and the resistance of the model ship is reduced at high speed.

VWC (no.2) model is designed to improve seakeeping performance in waves. Deadrise angles at A.P., midship, and F.P. are 17, 30, and 80 degrees, respectively. Deadrise angles rapidly increase from the midship to the bow, and forebody cross-sections are concave shapes for the wave-piercing in rough water. Deadrise angles slowly decrease from the midship to the stern for the prevention of resistance increase. Length-to-beam ratio of VWC model is larger than that of VPS model, which results in the improvement of seakeeping performance. The keel on the forebody is under the baseline, and it begins curving up toward the bow at $80 \%$ of the LWL forward of the transom. Therefore, wave impacts acting on the bow are reduced and vertical motion amplitudes are decreased in rough water. Two pairs of spray rails are installed on the bottom. The bottom of the stern is extended backward about $2.9 \%$ of the length of waterline as VPS model.

After analyzing the model test results for VPS and VWC models, VWS (no.3) model was designed in order to have both favorable resistance performance and seakeeping behavior simultaneously. Deadrise angles of VWS model are around 22 degrees on afterbody, and they are rapidly increased to the bow, up to 75 degrees. So VWS model is advantageous for wave- 
piercing, similar to VWC model. But deadrise angles of VWS model are totally a little smaller than those of VWC model. And cross-sections on the forebody of VWS model are the straight shapes. So VWS model is more advantageous to take lifts on the bow and to rise up than VWC model. In general, as a planing hull rises up higher, its seakeeping performance becomes worse. So length-to-beam ratio of VWS model increase to 3.872, more than that of VWC model, and the keel begins curving up toward the bow at $85 \%$ of the LWL forward of the transom for good seakeeping performance. The keel is located on the baseline at every cross section. There are 2 pairs of spray rails on the hull bottom. And, the bottom of the stern is extended backward $4.3 \%$ of the length of waterline to reduce the trim angle and the required power at high speed.
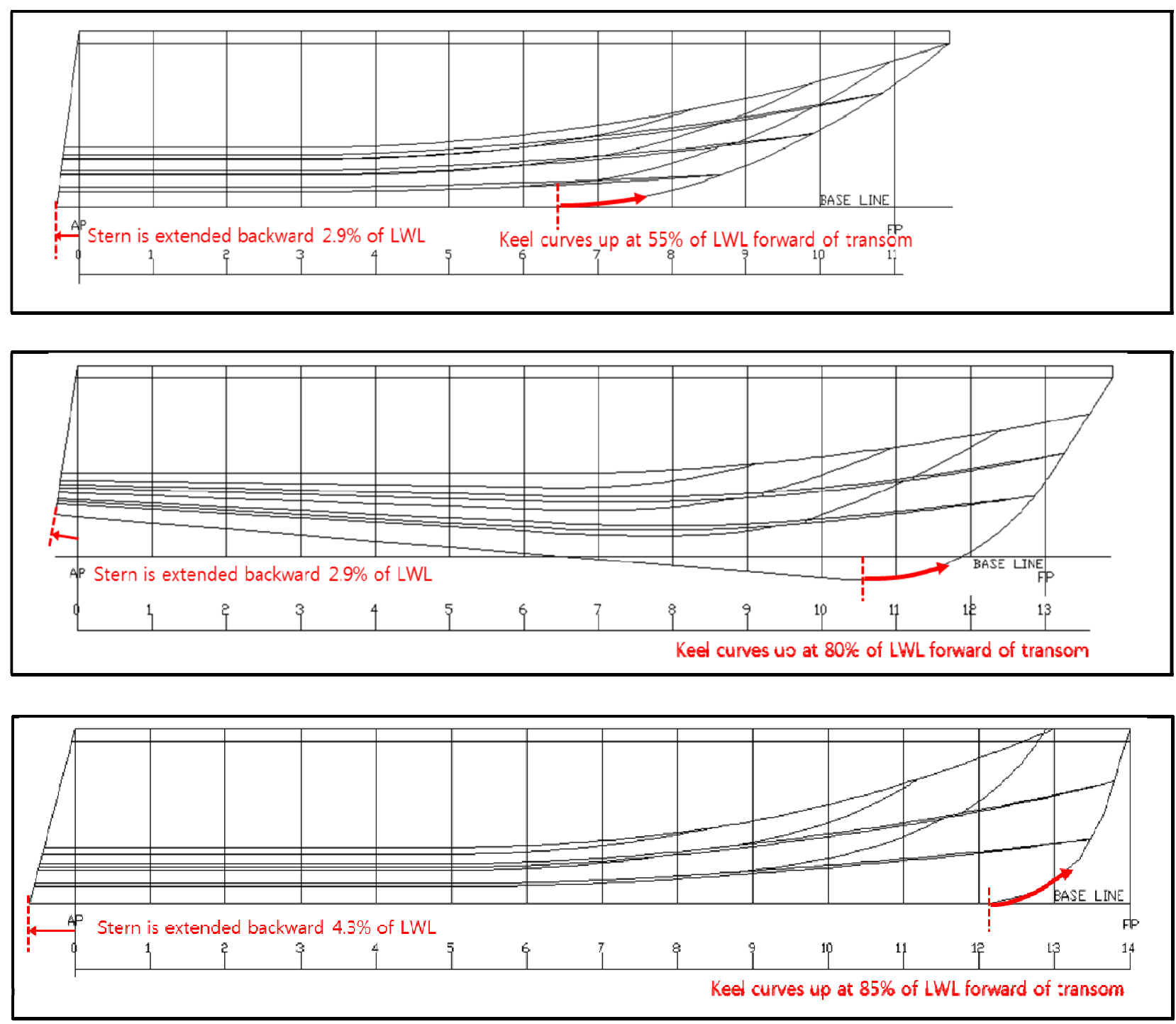

Fig. 5 Shear plans of no.1 (VPS; upper), no.2 (VWC; middle), and no.3 (VWS; lower) model ships.

\section{MODEL TESTS IN CALM WATER}

\section{Test conditions}

Rise of the center of gravity, trim and resistance of each model ship are measured at various speeds in calm water. Speeds are varied 5 to 45 knots at intervals of 5 knots in real ships. Corresponding towing speeds of model ships are 1.01 to $9.08 \mathrm{~m} / \mathrm{sec}$. Froude numbers are from 0.36 to 3.25 . Rise is positive upward, and trim angle is positive bow-up. 


\section{Model test results}

Running attitudes of model ships at maximum Froude number are shown in Fig. 6. Variations of rise, trim and resistance of each model ship with real ship speed are shown in Figs. 7 to 9. At maximum Froude number, the rises of VPS, VWC and VWS models are $75 \%, 50 \%$ and $70 \%$ of the initial draft, and trims are 3.5, 5.0 and 3.0 degrees, respectively.

The resistance of VPS model is largest at around 10 to $15 \mathrm{knots}$, but is smallest at speeds above 25 knots. VWC model has the largest resistance at high speed, above 25 knots. The resistance of VWS model at speeds above 25 knots is larger than that of VPS model and is smaller than VWC model.
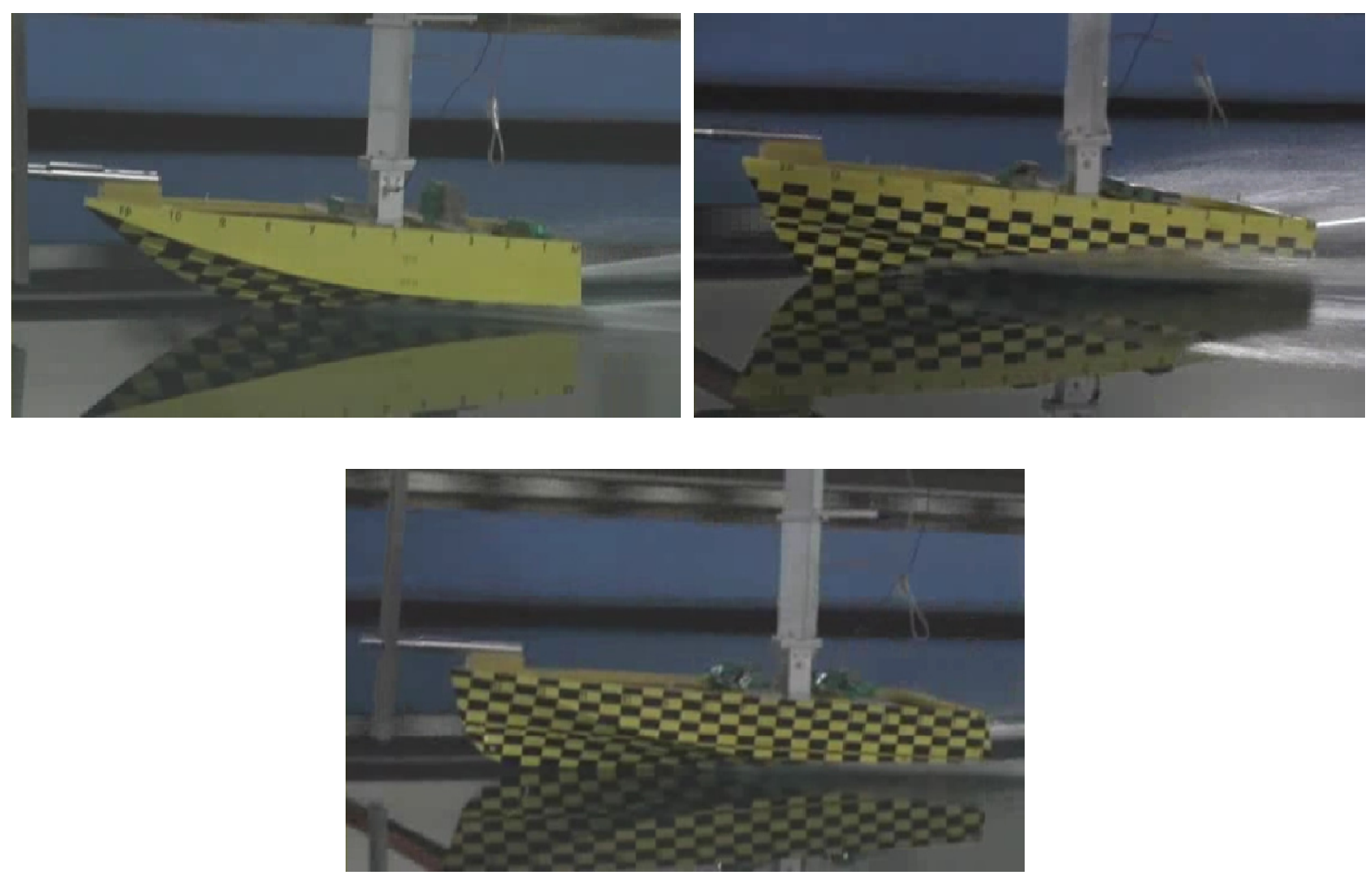

Fig. 6 Running attitudes of VPS (upper left), VWC (upper right), and VWS (lower) model at Fn =3.25.

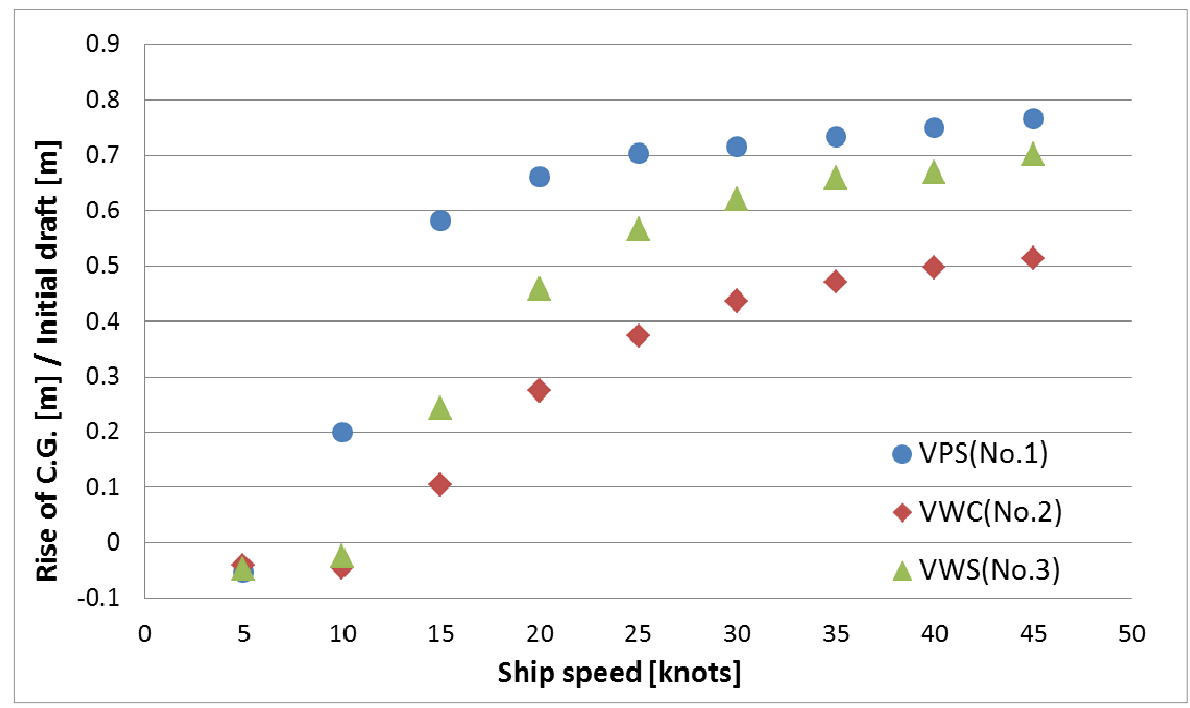

Fig. 7 Variation of rises with ship speed. 


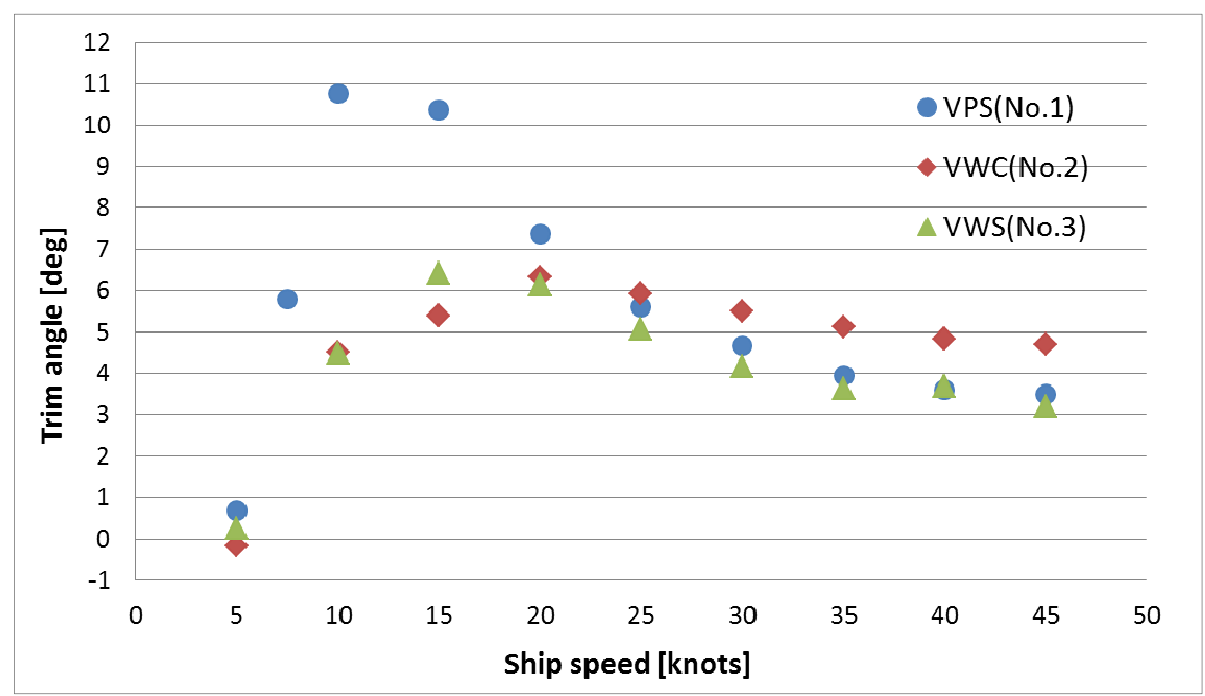

Fig. 8 Variation of trims with ship speed.

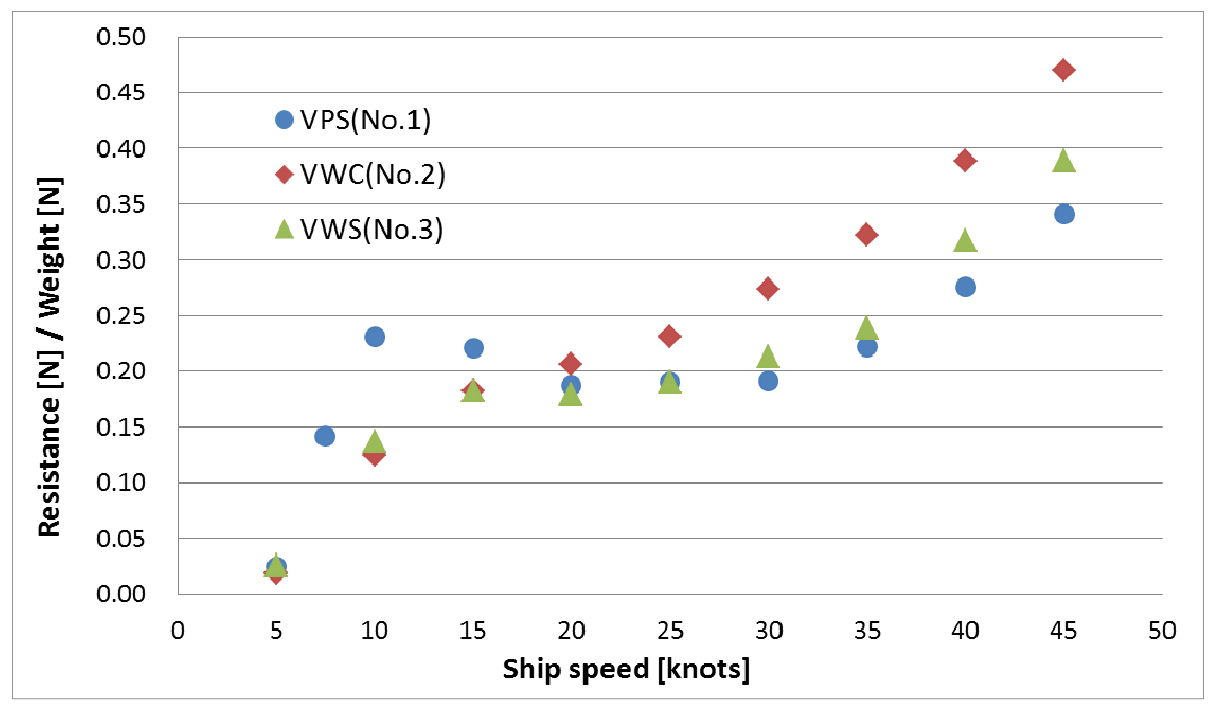

Fig. 9 Variation of resistances over weight with ship speed.

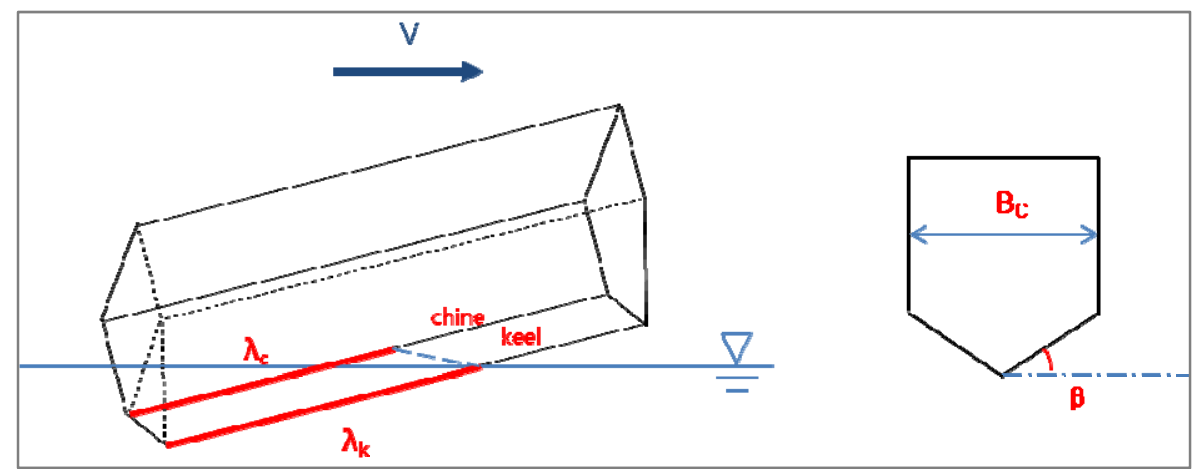

Fig. 10 Wetted bottom shape of a hard-chine planing hull.

In general, the wetted bottom shape of a hard-chine planing hull is as shown in Fig. 10. $L_{k}$ and $L_{c}$ are respectively the wetted keel length and the wetted chine length. Then the mean wetted length $L_{m}$ is obtained by Eq. (1). The wetted bottom surface area, $S$ is approximated by Eq. (2). $B_{c}$ is the chine breadth, $\beta$ is the deadrise angle. 


$$
\begin{aligned}
& L_{m}=\left(L_{k}+L_{c}\right) / 2 \\
& S=L_{m} \cdot B_{c} \cdot \cos \beta
\end{aligned}
$$

Total resistance $\left(R_{T}\right)$ is the sum of frictional resistance $\left(R_{F}\right)$ and residual resistance $\left(R_{R}\right)$. And the total resistance coefficient $\left(C_{T}\right)$ is obtained by Eq. (3). $\rho$ is the mass density of water, $V$ is the towing speed of the model ship.

$$
C_{T}=\frac{R_{T}}{1 / 2 \rho S V^{2}}
$$

Frictional resistance coefficients are obtained by ITTC 1957 model-ship correlation line (Lewis, 1988) as shown in Eq. (4). Reynolds number, $R_{N}$ in Eq. (4) is calculated by using the towing speed and the mean wetted length of the model ships.

$$
C_{F}=\frac{0.075}{\left(\log _{10} R_{N}-2\right)^{2}}
$$

Residual resistance coefficient, $C_{R}$ is calculated as Eq. (5).

$$
C_{R}=C_{T}-C_{F}
$$

Resistance components of the three model ships at 10, 25, and 45 knots are shown in Fig. 11. VPS model has larger trim angles than VWC and VWS models at speeds around 10 knots. So the residual resistance components of VPS model are largest at 10 knots. For all model ships, residual resistance is larger than frictional resistance at speeds under 25 knots, but frictional resistance becomes larger than residual resistance at high speed, over 25 knots.

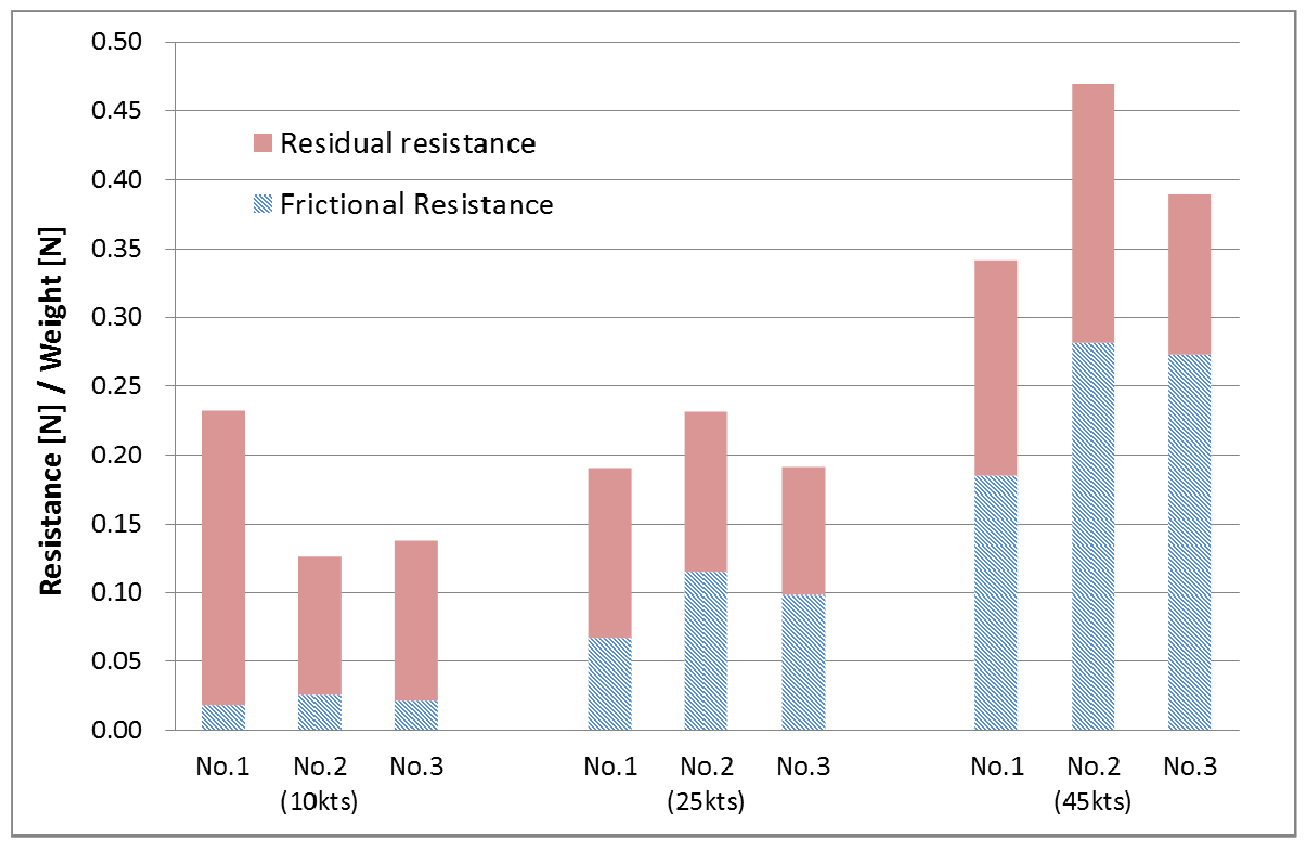

Fig. 11 Resistance components of model ships at 10, 25 and 45 knots. 


\section{'Porpoising' phenomenon}

The bottom of VPS model is extended backward from the A.P. section, by $2.9 \%$ of the length of waterline. And then, the extended length of the bottom of VPS model doubles to reduce trim angles and required powers at high speed. A side view of the extended stern of VPS model is shown in Fig. 12.

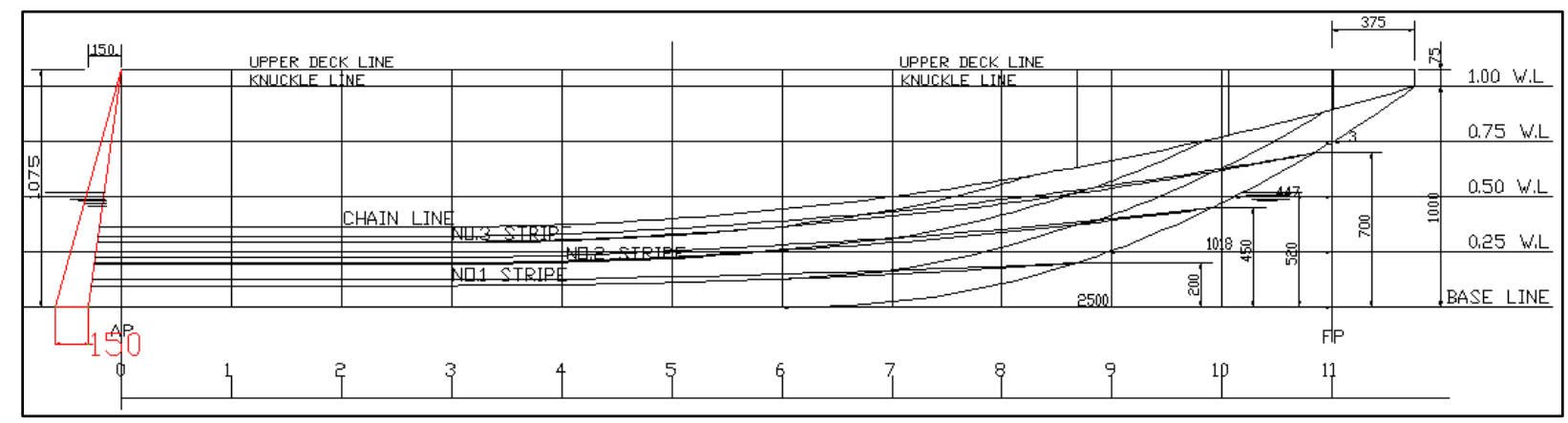

Fig. 12 Side view of stern extension of VPS model ( $+2.9 \%$ of length of waterline).

It was predicted that the running trim and resistance of VPS model would be changed due to the bow-down moment caused by the extended hull bottom. After modifying the hull bottom as above, however, there were no significant changes in running attitude and resistance of VPS model at 10 to $40 \mathrm{knots}$, and porpoising phenomenon occured at 30 knots. Sinkage and trim under porpoising oscillate largely, as shown in Fig. 13. To prevent the porpoising phenomenon, it is effective to add appendages at the stern for generating a lot of bow-down moments.

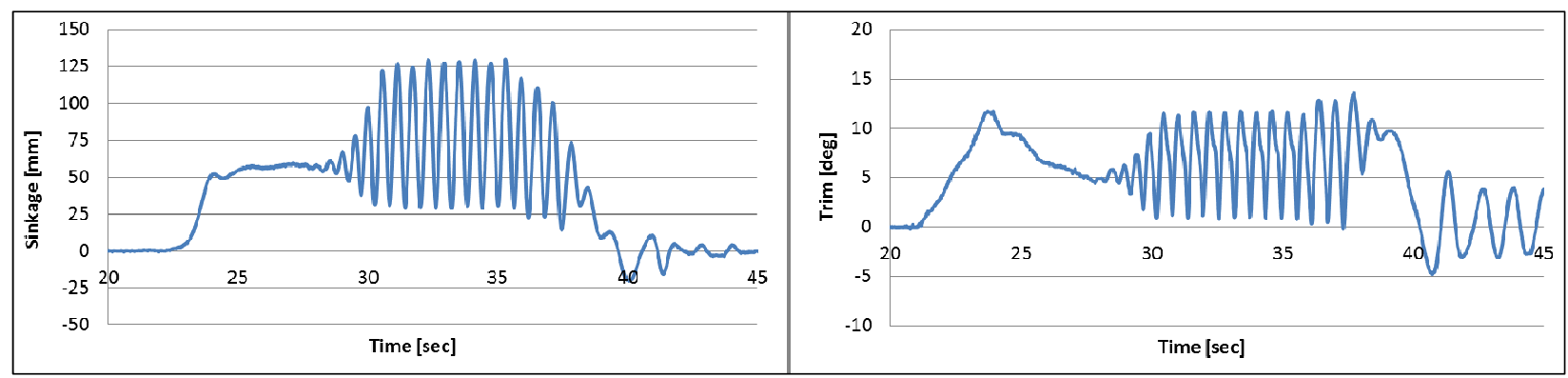

Fig. 13 Unstable heave and pitch motions for stern extended VPS model in calm water tests (30 knots).

\section{MODEL TESTS IN REGULAR WAVES}

\section{Test conditions}

Heave and pitch motions are measured in regular waves with various wave lengths. Wave amplitude is $0.02 \mathrm{~m}$, towing speed of the model ship is fixed as $4.04 \mathrm{~m} / \mathrm{sec}$ (Froude number is 1.44). In real ship scale, wave height is $0.26 \mathrm{~m}$, ship speed is 20 knots. Wave lengths are varied from $2.0 \mathrm{~L}$ to $7.0 \mathrm{~L}$ for three model ships. ' $L$ ' is the waterline length of each model ship. Seven regular waves are generated for VPS model $(3.0 \mathrm{~L}$ to $7.0 \mathrm{~L})$ and VWC model $(2.0 \mathrm{~L}$ to $6.5 \mathrm{~L})$. And nine regular waves are generated for VWS model $(2.0 \mathrm{~L}$ to $7.0 \mathrm{~L})$.

\section{Model test results}

Figs. 14 to 16 show the snapshots of vertical motions of each model ship at resonant frequency in regular waves. Photographs are taken at the time interval of 0.33 seconds. 

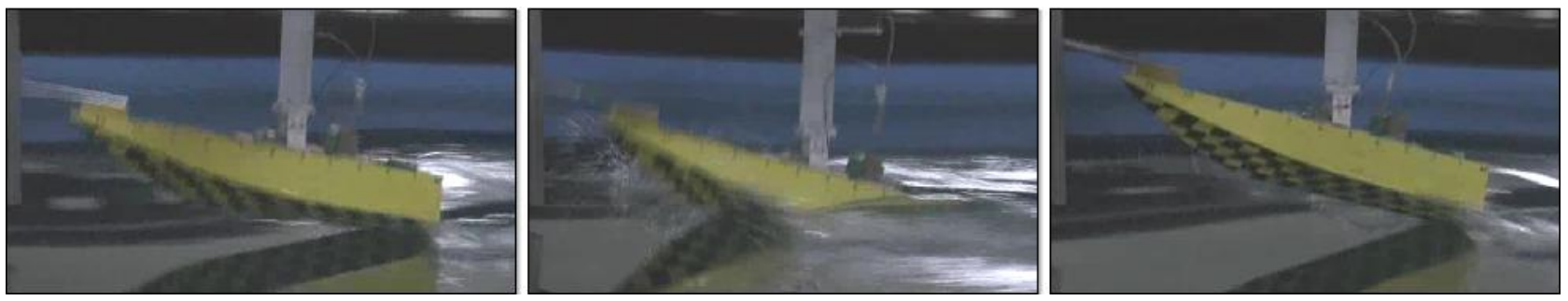

Fig. 14 Snapshot of VPS model at Fn $=1.44$ (wave length $: 6.0 \mathrm{~L}$ ).
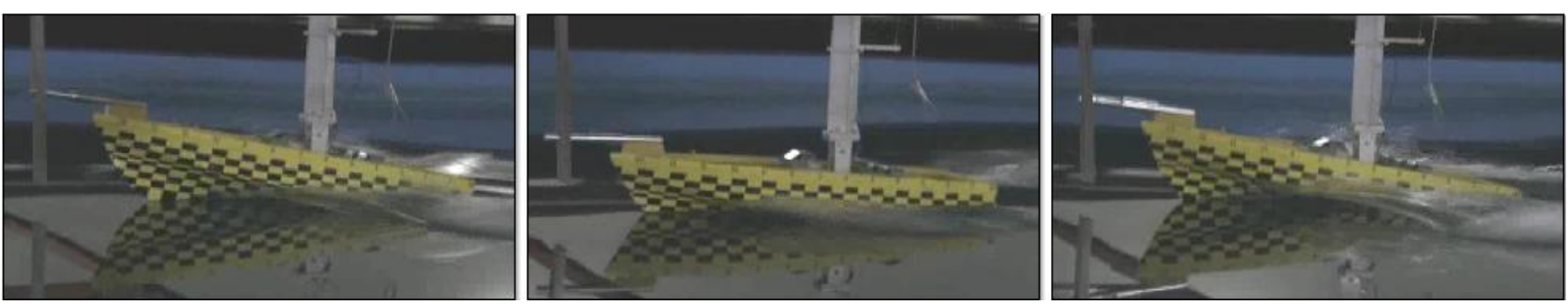

Fig. 15 Snapshot of VWC model at Fn $=1.44$ (wave length : $5.0 \mathrm{~L}$ ).
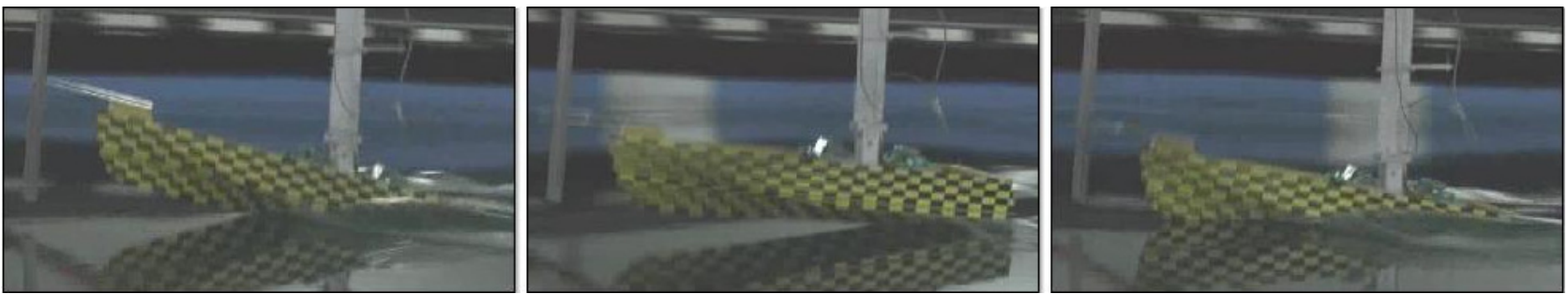

Fig. 16 Snapshot of VWS model at Fn $=1.44$ (wave length : $4.5 \mathrm{~L}$ ).

VPS model shows the 'fly over' phenomenon around its resonant frequency in regular waves. The bow of VWC model does not come out of the water, and its motion amplitude is relatively small. The bow of VWS model comes out of the water around its resonant frequency, but does not fly over. Maximum heave and pitch motion amplitudes of VWS model are smaller than those of VPS model, and are larger than those of VWC model.

Figs. 17 and 18 show the heave and pitch transfer functions and phases of three model ships. Heave and pitch motion amplitudes are non-dimensionalized by wave amplitudes and wave slopes, respectively. The unit of phase is degree, positive phase means 'phase lead'.
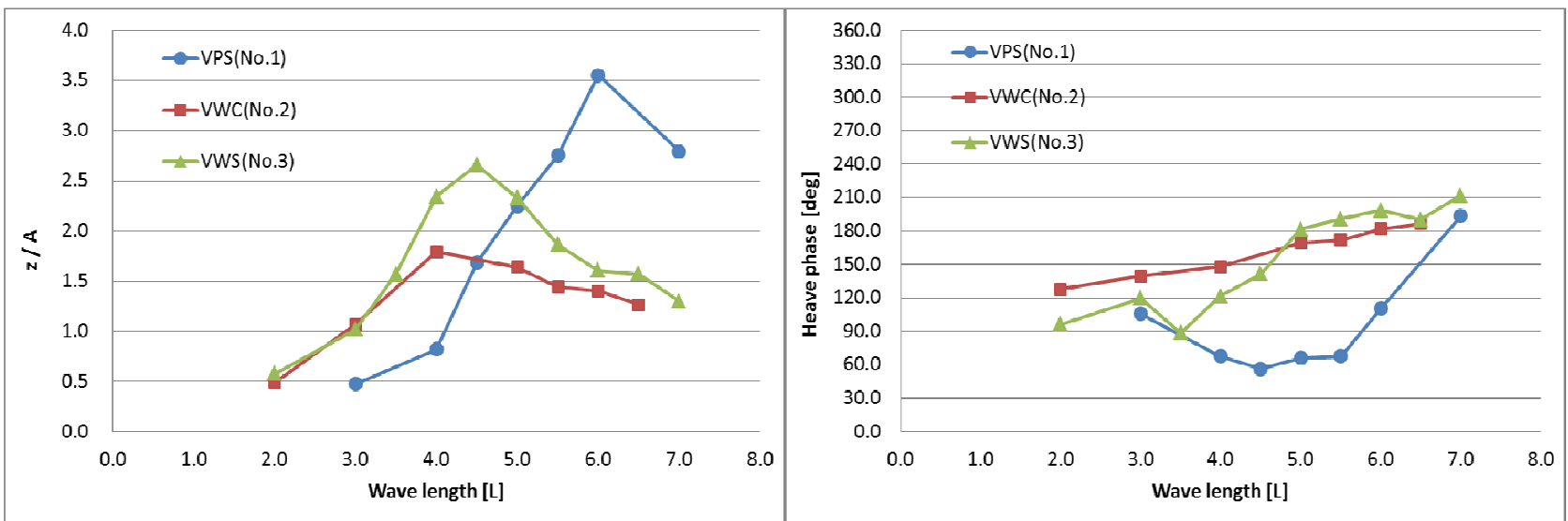

Fig. 17 Heave transfer functions (left) and heave phases (right) of model ships. 


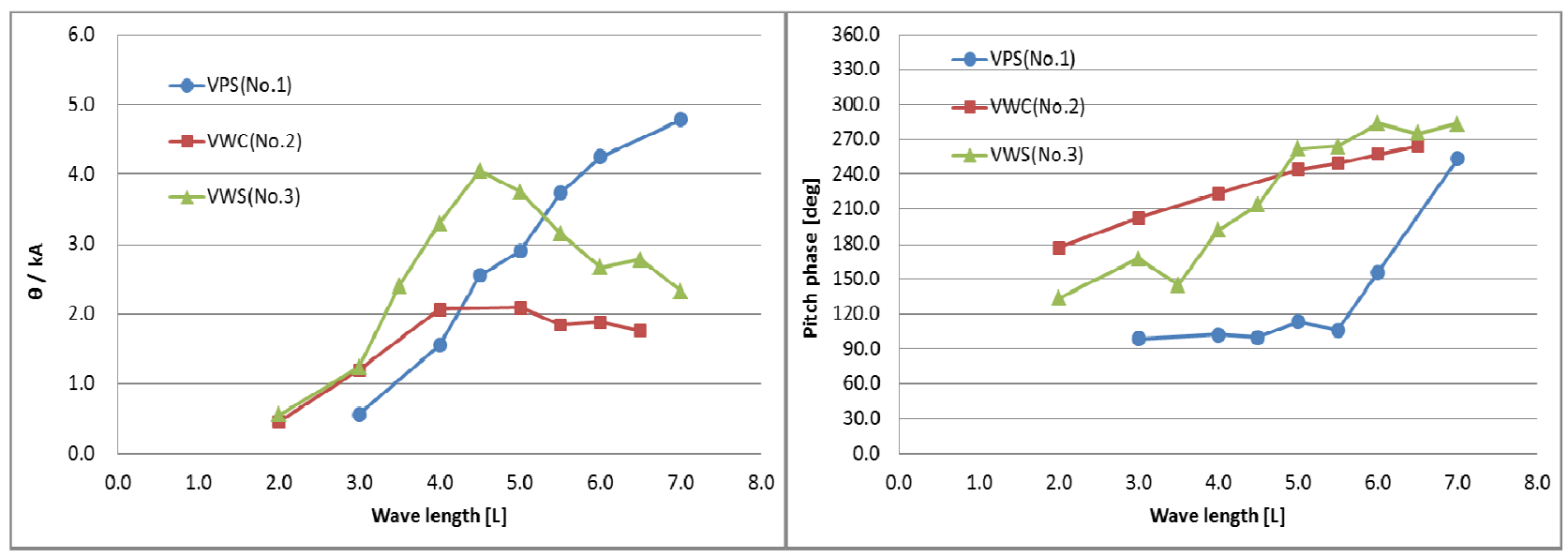

Fig. 18 Pitch transfer functions (left) and pitch phases (right) of model ships.

Heave transfer functions of VPS, VWC and VWS models at resonant frequencies are respectively 3.5, 1.8 and 2.6. And their pitch transfer functions at resonant frequencies are 5.0, 2.1 and 4.0. The heave and pitch phase of VPS model is about 90 degrees when the wave length is less than 5.5. And those rapidly increase around resonant frequency to be about 180 degrees. The heave and pitch phase of VWC and VWS models are around 180 degrees, and are slowly increased as the wave length becomes larger.

\section{'Fly over' phenomenon}

Fridsma (1969), Martin (1976) measured a phenomenon that planing hulls come out of the wave elevation completely in model tests, and they called that phenomenon 'fly over'. 'Fly over' occurs in present model tests for VPS model at Froude number 1.44. Fig. 19 shows the positions of baseline at A.P., C.G. (center of gravity), and F.P. The model ship is turned out to 'fly over' when all three positions come out of the water.

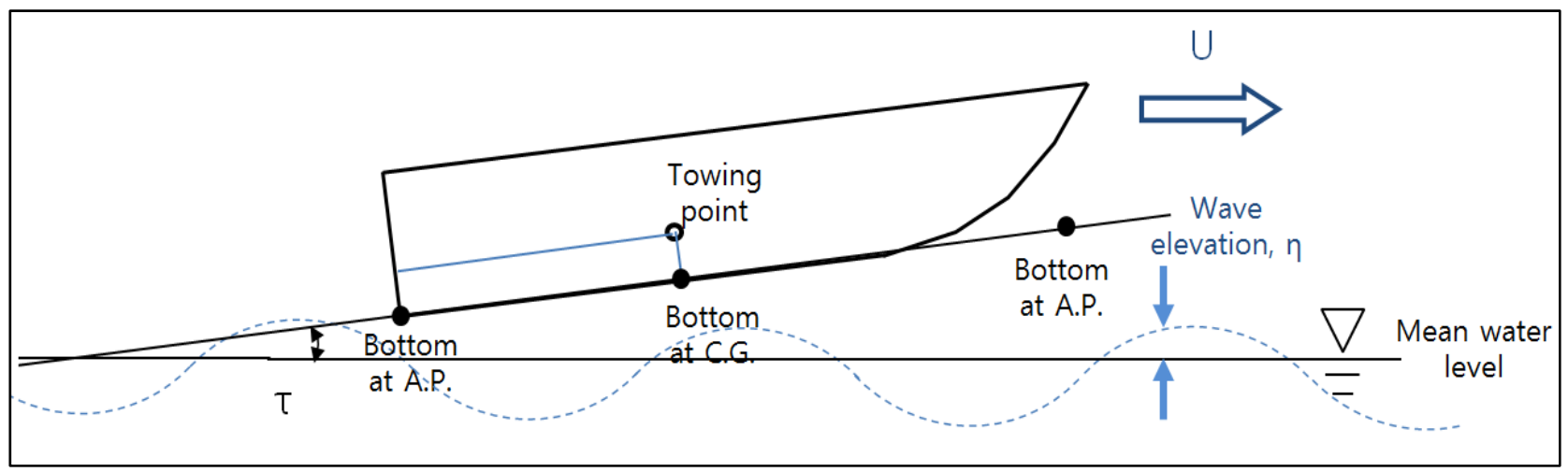

Fig. 19 Side view of a model ship and wave elevation.

Time histories of heave, pitch motions and wave elevations are obtained by model tests. Wave elevations and baseline positions at A.P., C.G. and A.P. are re-plotted at the time interval of 0.1 seconds, as shown in Table 3 . It is easy to check whether or not the model ships fly over through the graphs in Table 3.

For VPS model, there are 'fly over' phenomena when the wave length is $5.0 \mathrm{~L}$ to $7.0 \mathrm{~L}$. In particular, irregular 'fly over' occurs when the wave length is $7.0 \mathrm{~L}$. If the same phenomena occur in a real ship, vertical motion amplitude may be too large, and become unstable. Fig. 20 shows the 'fly over' zone of VPS model. 
Table 3 Wave profiles and bottom height at A.P., C.G. and F.P.

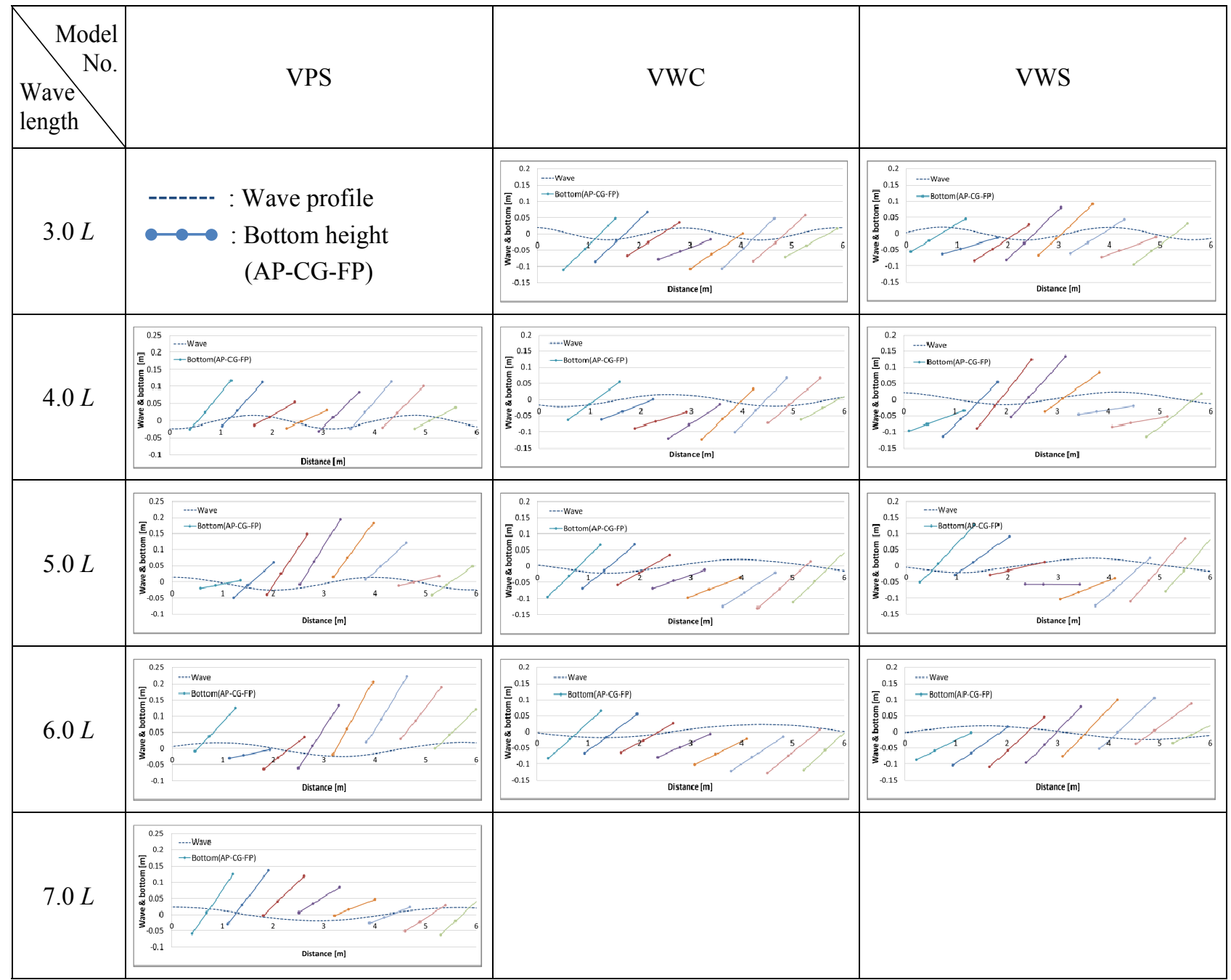

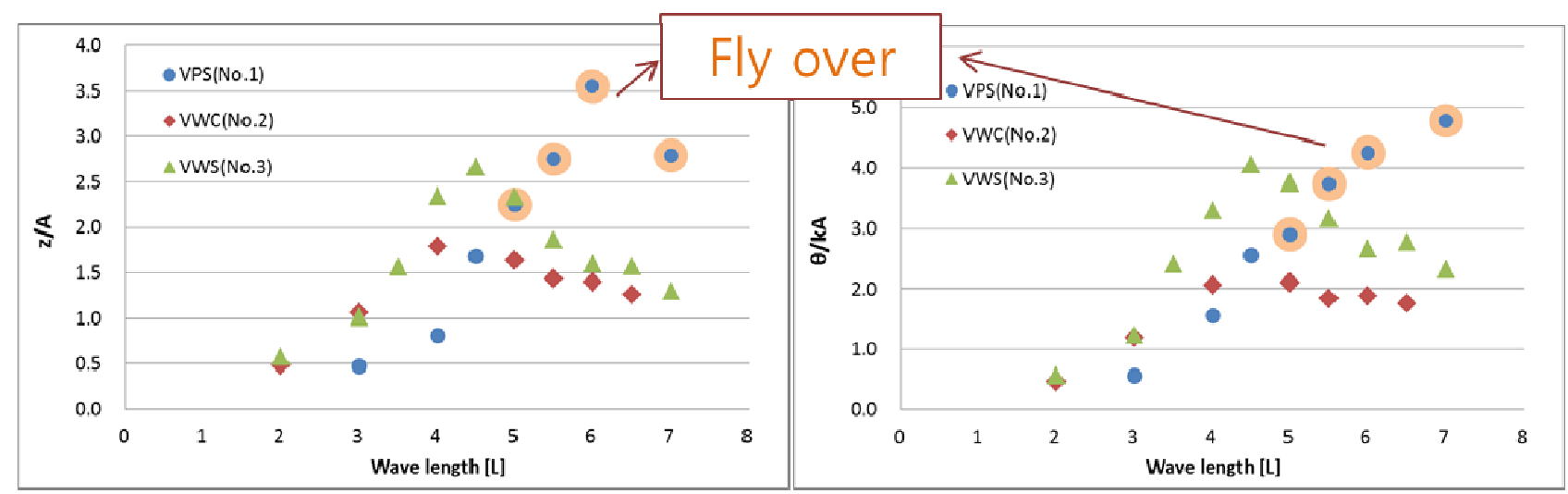

Fig. 20 'Fly over' zone in regular waves $(\mathrm{Fn}=1.44)$.

\section{Vertical acceleration}

Vertical accelerations are measured at the resonant frequency of each model ship. Test conditions for measuring vertical accelerations are shown in Table 4. Vertical accelerations of VWC model are measured when the wave amplitude is $0.01,0.02$, and $0.03 \mathrm{~m}$ to check the effects of wave amplitudes on the vertical accelerations. Accelerometers Acc1, Acc2 and Acc3 are located at C.G., F.P. and the middle between C.G. and F.P., as shown in Table 5. 
Table 4 Test conditions for measuring vertical accelerations at resonant frequencies of model ships.

\begin{tabular}{|c|c|c|c|}
\hline & VPS model & VWC model & VWS model \\
\hline \multirow{2}{*}{ Wave amplitude $[\mathrm{m}]$} & 0.02 & 0.01 & 0.02 \\
& & 0.02 & \\
\hline Wave length $[L]$ & 6.0 & 0.03 & 4.5 \\
\hline
\end{tabular}

Table 5 Locations of accelerometers.

\begin{tabular}{|c|c|c|c|c|c|c|}
\hline \multirow{2}{*}{ Accelerometer } & \multicolumn{2}{|c|}{ VPS model } & \multicolumn{2}{c|}{ VWC model } & \multicolumn{2}{c|}{ VWS model } \\
\cline { 2 - 7 } & $\begin{array}{c}\text { Station } \\
\text { No. }\end{array}$ & $\begin{array}{c}\text { Distance from } \\
\text { F.P. }[\mathrm{m}]\end{array}$ & $\begin{array}{c}\text { Station } \\
\text { No. }\end{array}$ & $\begin{array}{c}\text { Distance } \\
\text { from F.P. }[\mathrm{m}]\end{array}$ & $\begin{array}{c}\text { Station } \\
\text { No. }\end{array}$ & $\begin{array}{c}\text { Distance from } \\
\text { F.P. }[\mathrm{m}]\end{array}$ \\
\hline Acc1 & 3.7 (C.G.) & 0.56 & 5.5 (C.G.) & 0.58 & 4.6 (C.G.) & 0.72 \\
\hline Acc2 & 7.4 & 0.28 & 9.2 & 0.29 & 9.3 & 0.36 \\
\hline Acc3 & 11.0 (F.P.) & 0.00 & 13.0 (F.P.) & 0.00 & 14.0 (F.P.) & 0.00 \\
\hline
\end{tabular}

Fig. 21 shows the time histories of vertical accelerations at F.P. of the three model ships. Accelerations are positive upward. VPS model has the largest vertical acceleration. VPS model repeatedly comes out of water and free falls. Bow-down moments are generated when the bottom of A.P. of VPS model touches the free surface, so there are negative peak accelerations, as well as positive peaks due to bow slamming. Vertical accelerations of VWC model are relatively small and there are no clear peak values, since the bow of VWC model does not come out of the free surface. Some parts of the bow of VWS model come out of the water, so there are instantaneous positive peaks like VPS model, but the peak accelerations of VWS model are smaller than those of VPS model, and are larger than those of VWC model.

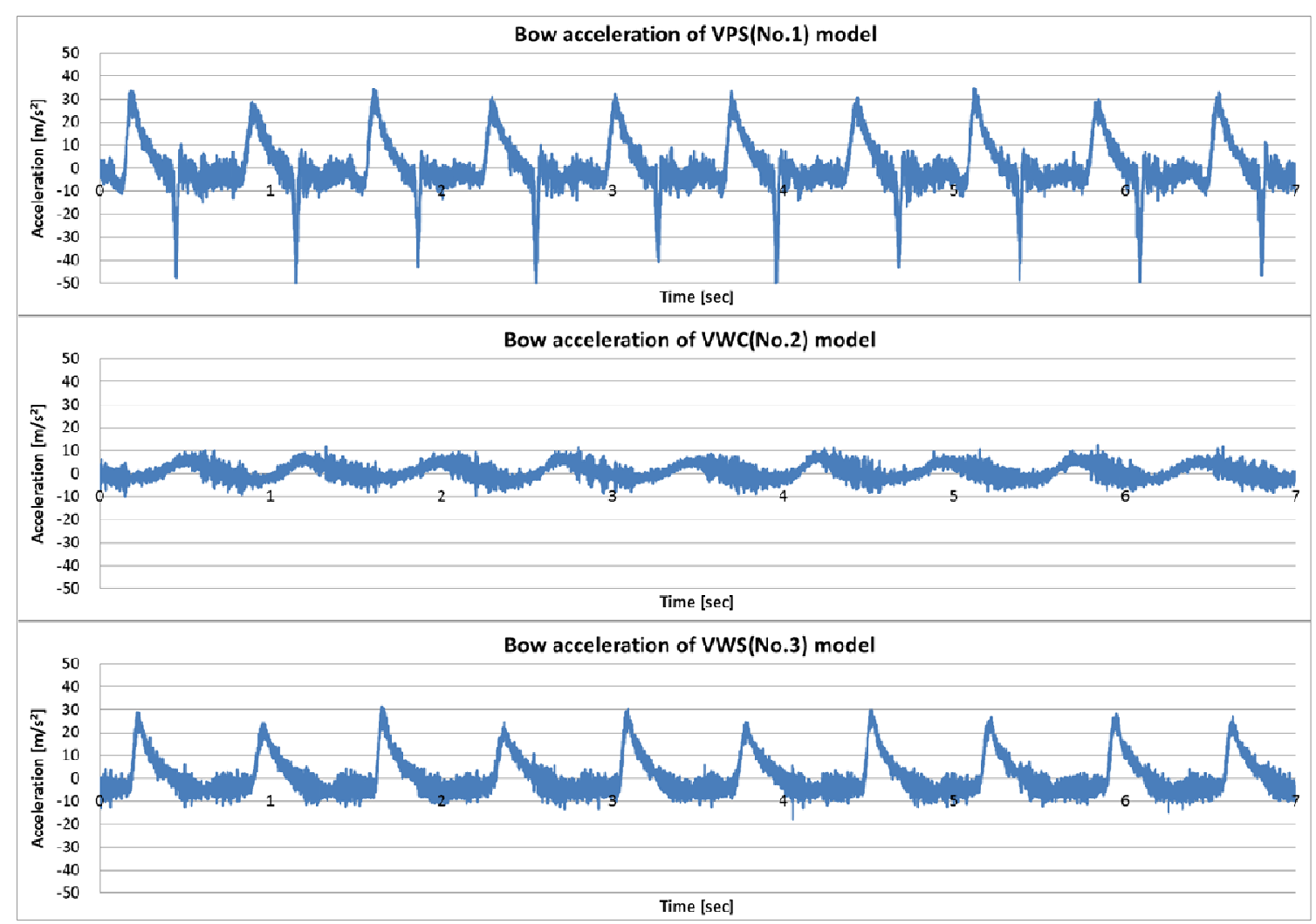

Fig. 21 Vertical accelerations at F.P. of VPS (upper), VWC (middle), and VWS (lower) model. 
Peak accelerations of each model ship are shown in Table 6. Vertical accelerations due only to heave motions are measured at C.G.. Vertical accelerations become larger, as it is closer to the bow, because vertical accelerations due to pitch motions are added. Taken in the same location, VPS model has the largest vertical accelerations, and VWC model has the smallest vertical accelerations.

The vertical accelerations of VWC model according to wave amplitude are shown in Table 7. Vertical accelerations increase proportionally to the wave amplitude.

Table 6 Maximum vertical acceleration of VPS, VWC and VWS models.

\begin{tabular}{|c|c|c|c|c|}
\hline Model & Wave amplitude $[m]$ & Acc1 $(\mathrm{LCG})$ & Acc2 & Acc3 (F.P.) \\
\hline \multirow{2}{*}{ VPS } & \multirow{3}{*}{0.02} & $1.5 \mathrm{G}$ & $2.8 \mathrm{G}$ & $3.2 \mathrm{G}$ \\
\cline { 1 - 4 } & & $0.8 \mathrm{G}$ & $1.0 \mathrm{G}$ & $1.1 \mathrm{G}$ \\
\cline { 3 - 5 } VWC & & $1.2 \mathrm{G}$ & $2.3 \mathrm{G}$ & $2.8 \mathrm{G}$ \\
\hline
\end{tabular}

Table 7 Maximum vertical acceleration of VWC model according to wave amplitude.

\begin{tabular}{|c|c|c|c|c|}
\hline \multirow{2}{*}{ Model } & Wave amplitude $[m]$ & Acc1 $(\mathrm{LCG})$ & Acc2 & Acc3 (F.P.) \\
\hline \multirow{3}{*}{ VWC } & 0.01 & $0.5 \mathrm{G}$ & $0.7 \mathrm{G}$ & $0.8 \mathrm{G}$ \\
\cline { 2 - 5 } & 0.02 & $0.8 \mathrm{G}$ & $1.0 \mathrm{G}$ & $1.1 \mathrm{G}$ \\
\cline { 2 - 5 } & 0.03 & $1.1 \mathrm{G}$ & $1.3 \mathrm{G}$ & $1.4 \mathrm{G}$ \\
\hline
\end{tabular}

Vertical accelerations can be also obtained by differentiating measured heave and pitch displacements with respect to time. Fig. 22 shows one example of the comparisons of vertical accelerations measured directly by accelerometers, with vertical accelerations obtained by differentiating vertical displacements indirectly. The thin dotted line is the vertical accelerations at F.P. of VPS model, measured by accelerometers on a frequency of 2,560 Hz. And the solid line indicates the second derivatives of vertical displacements with respect to time at the same location on a frequency of $100 \mathrm{~Hz}$. The thick dotted line is a re-plotted line obtained by changing the frequency of accelerometers from 2,560 Hz to $100 \mathrm{~Hz}$. As shown in Fig. 22, second derivatives of vertical displacements with respect to time are less than half the vertical accelerations measured by accelerometers. And there are no significant changes on the peak values if accelerations are measured at high frequency, more than $100 \mathrm{~Hz}$. After all, it is necessary to directly measure vertical accelerations by accelerometers to accurately predict about vertical accelerations.

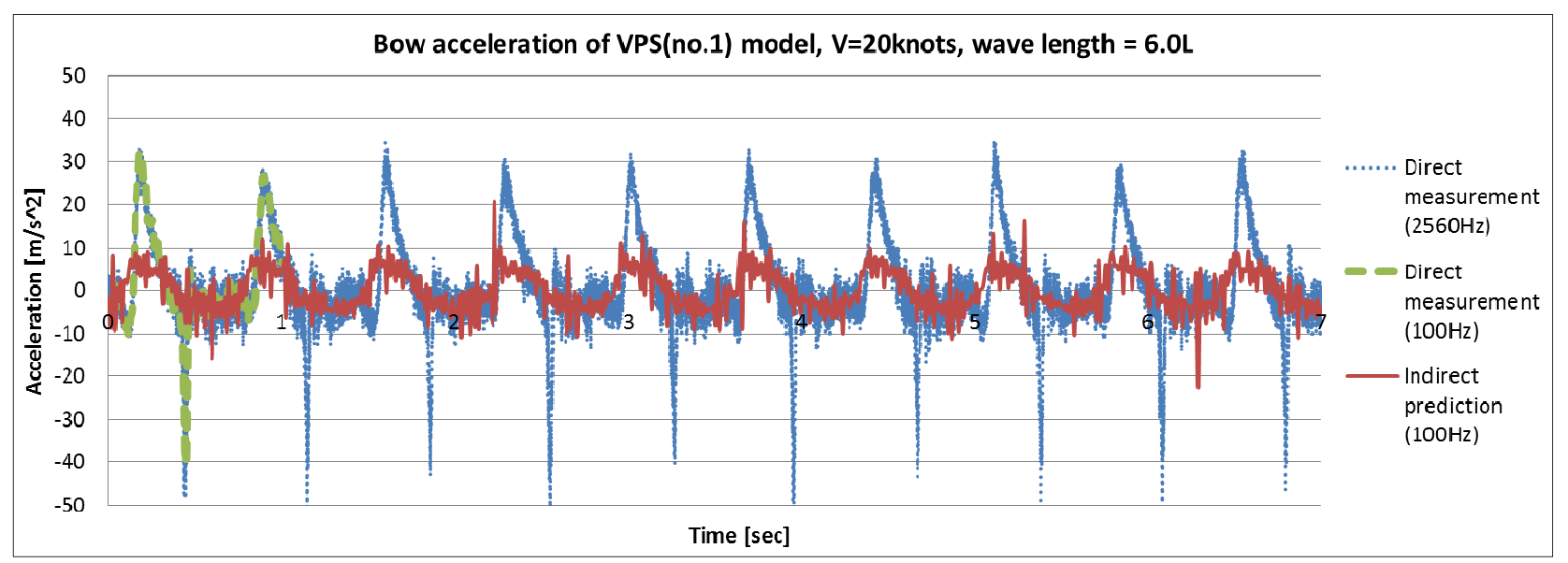

Fig. 22 Comparison of predicted acceleration by heave/pitch motions with measured acceleration. 


\section{CONCLUSIONS}

The purpose of this study is to design a high-speed planing hull which has good resistance and seakeeping performance. Three high-speed planing hulls that have almost same displacement are designed, their hydrodynamic performance are predicted and compared with each other through the high-speed model tests.

Effects of design parameters such as deadrise angle, cross-section shape, length-to-beam ratio, forefoot contour, etc. on the hydrodynamic performance of the hull are experimentally investigated. Small deadrise angles make the hull rise up higher, and those have a significant influence on the resistance decrease. But small deadrise angles lead to the large vertical motion of the hull in waves. When the keel line begins curving up toward the bow near the F.P., in other words, deadrise angles at the bow are large, the hull shows small vertical motion amplitudes in waves. And seakeeping performance of the hull is improved with large length-to-beam ratio. Extended stern bottom is advantageous to the resistance reduction, but in some cases, the stern appendages such as trim tabs may be required to prevent unstable phenomenon.

VPS (no.1) model that shows the smallest resistance at high speed (above 30 knots), has the largest residual resistance at low speed (around 10 knots) due to large running trim. If the real ship operates at low speed frequently, it should be designed to have small trim angle at low speed. Frictional resistance is dominant at high speed, so it is effective to reduce the wetted surface area in order to decrease the hull resistance in high speed region.

When the planing hull is designed in order that the bow bottom hardly comes out of water, its vertical motion amplitudes becomes small in waves. And there is little possibility of 'fly over' phenomenon. Therefore, if the real ship often operates in rough water, the hull should be designed in order that the bow comes out of the waves as little as possible.

In this study, VWS model has favorable resistance and seakeeping performance among the three model ships. Its hull form will be optimized to improve its hydrodynamic performance in the near future. And, stern appendages may be effective for reducing its required power. For good seakeeping performance, the bow shape is to be designed as a wave-piercing type.

\section{ACKNOWLEDGEMENTS}

This research was supported by the Ministry of Land, Transport and Maritime Affairs of Korea under the project, 'Development of multi-purpose intelligent unmanned surface vehicle' of MOERI/KIOST as well as Marine Technology Education and Research Center of Brain Korea 21 at Seoul National University.

\section{REFERENCES}

Fridsma, G., 1969. A systematic study of the rough-water performance of planing boats. Davidson Laboratory Report 1275 , Stevens Institute of Technology.

Gerritsma, J., Keuning, J.A. and Versluis, A., 1993. Sailing yacht performance in calm water and in waves. 11th Chesapeake Sailing Yacht Symposium, Annapolis, USA January 29-30 1993. Society of Naval Architects and Marine Engineers. Chesapeake Section.

Ikeda, Y., Katayama, T., Yamashita, Y., Otsuka, K. and Maeda, T., 1995. Development of an experimental method to assess the performance of a high speed craft(1st Report) - Development of a high speed towing system. Journal of Kansai Society of Naval Architects, 223, pp.43-48.

Ikeda, Y., Nishida, G., Katayama, T., Yamaguchi, Y., Niina, J. and Oshima, T., 1996. Development of an experimental method to assess the performance of a high speed craft(2nd Report) - Hydrodynamic forces acting on series models running with high speed. Journal of Kansai Society of Naval Architects, 226, pp.77-84.

Katayama, T., Hinami, T. and Ikeda, Y., 2000. Characteristics of motion for planing craft in head wave at very high-speed. Journal of Kansai Society of Naval Architects, 233, pp.55-62.

Kim, D.J., Rhee, K.P. and Park, H.S., 2009a. A study on the effects of weight and center of gravity of a planing craft on running attitude. Journal of the Society of Naval Architects of Korea, 46(3), pp.335-342.

Kim, D.J., Rhee, K.P., Hwang, S.H. and Park, H.S., 2009b. An experimental study on the motion response of a high-speed planing craft in regular head waves. Journal of the Society of Naval Architects of Korea, 46(4), pp.373-381. 
Kim, J., Jeong, U., Park, J. and Kim, D., 2006. A study on the initial hull form development and resistance performance of a 45 knots class high-speed craft. Journal of Ocean Engineering and Technology, 20(1), pp.32-36.

Lee, K., Park, N. and Lee, E., 2005. An experimental study on the improvement of resistance performance by appendage for 50knots class planing hull form. Bulletin of the Korean Society of Fisheries Technology, 41(3), pp.222-226.

Lewis, E.V., 1988. Principles of Naval Architects (Second Revision), Volume II. The Society of Naval Architects and Marine Engineers, pp.7-15.

Martin, M., 1976. Theoretical prediction of motions of high-speed planing boats in waves. DTNSRDC Report 76-0069, David W. Taylor Naval Ship Research and Development Center.

Savitsky, D. and Brown, P.W., 1976. Procedures for hydrodynamic evaluation of planing hulls in smooth and rough water. Marine Technology, 13(4), pp.381-400. 